\title{
End-of-use and end-of-life medicines-insights from pharmaceutical care process into waste medicines management
}

\author{
Elaine Aparecida Regiani de Campos $^{1}$ (D) $\cdot$ Carla Schwengber ten Caten ${ }^{1}$ (D) Istefani Carísio de Paula ${ }^{1}$ (i)
}

Received: 20 March 2020 / Accepted: 27 May 2021 / Published online: 9 June 2021

(C) The Author(s), under exclusive licence to Springer-Verlag GmbH Germany, part of Springer Nature 2021

\begin{abstract}
End-of-use and end-of-life medicines waste management has been a challenge for public and private managers in different countries. Reverse logistics is a waste management strategy whose application to public pharmaceutical care processes faces legal restrictions and incertitude. Nevertheless, reverse logistics of end-of-use and end-of-life medicines may be both a saving and an environmental strategy in developing countries that manage health under limited resources. How to overcome restrictions to reverse logistics mainly in the context of primary health level? This study aims to investigate the most relevant critical factors for implementing medicine waste management in pharmaceutical care process. The unit analysis is the primary health level process in a developing country capital. Considering the characteristics of the issue at hand, it was designed a qualitative study. Data was collected through semi-structured interviews. The interviewees were key individuals who work directly with the process-from administering medicine to patients to managing waste at the end of the medicine's lifespan or after its use. Results indicated that despite reverse logistics arising from end users is legally forbidden, another type of reverse flow emerged from process analysis. The reverse flow, named reassignment flow, consists of still useful end-of-use medicines exchanged among the 10 governmentran pharmacies and over 140 health centers, where healthcare professionals administer and offer guidance on how to use them correctly. Another result was the identification of the most critical factors in implementing reverse logistics strategies in the public management context. The factors mentioned included aspects pertaining to management, information technology, infrastructure, and government, but they differ from the private context management, in which decision-makers has more freedom. Due to the barriers named by interviewees, the political barriers and complexity of primary health system, results of this investigation point to (i) reinforcing the reassignment flows inside pharmaceutical care logistics cycle, for saving purposes, and (ii) further development of a specific management unit to perform reverse logistics of end-of-use medicines arising from consumers, for environmental purposes. In times of shortage or resources caused by the COVID-19 pandemic, to know the critical factors is a step necessary in overcoming the current restrictions in direction of a well-succeeded medicines reverse logistics, either of reassignment or from final consumers. These results clarify the literature on end-of-use and end-of-life medicines reverse logistics. It also provides managers of 5000 municipalities in the country a perspective on the most relevant critical factors involved in their decision-making process, concerning the reuse of end-of-use medicines or the adequate disposal of end-of-life medicines in the environment.
\end{abstract}

Keywords Pharmaceutical care process $\cdot$ Waste management $\cdot$ End-of-use and end-of-life medicines $\cdot$ Reverse logistics $\cdot$ Medicine disposal

Responsible Editor: Philippe Garrigues

Elaine Aparecida Regiani de Campos

earcamp@gmail.com

Carla Schwengber ten Caten tencaten@producao.ufrgs.br

Istefani Carísio de Paula

istefanicpaula@gmail.com

1 Universidade Federal do Rio Grande do Sul, Porto Alegre, Brazil

\section{Introduction}

Products with a shorter lifespan, which quickly become waste, have led to the changes on how institutions work. They make an effort to change product design to make those products less damaging to the environment at the end of their lifecycle. Managers have also changed their production processes, to include sustainable management of resources and assets and investments in reverse logistics-which is deemed an 
essential part of direct logistics (Aksoylu and Demirel 2018; Geethan et al. 2011; Rogers and Tibben-lembke 2001).

For different industries throughout the world, the commitment to create effective logistical processes is increasingly important (Ding 2018), with both the bottom line and the environment in mind (Geethan et al. 2011; Kabir 2013; Viegas et al. 2019).

Reverse logistics practices, which seek to return products at the end of their lifespan, allow value to be accrued and those products to be reverted into new technical and/or biological cycles, as advocate circular economy Bernon et al. 2018; Fischer and Pascucci 2017) and green supply chain (Mathiyazhagan et al. 2014; Luthra et al. 2011). Despite reverse logistics has evolved in different industrial segments, it is still limited in pharmaceutical organizations and health processes, as demonstrated by Campos et al. (2017).

As for pharmaceuticals, waste creation is even more concerning given the growing consumption of medications caused by factors such as development of new drugs, increase in life expectancy, and search for a better quality of life. They create greater dependency of the use of medicines (Massoud et al. 2016; Tong et al. 2011). Estimates show a global growth trend for the pharmaceutical industry, which is associated with greater consumption of medicaments, population growth and aging, easier access to drugs, and other factors. Further estimates for the future indicate that the global worth of the pharmaceutical industry will reach around USD 1.57 trillion by 2023 (Navadhi 2019).

Nevertheless, recently due to the COVID-19 pandemic, there has been an increase in the consumption of medicines by patients and also in the generation of waste in health units through the compulsive use of individual protection equipment (IPEs) such as masks, gloves, and disinfectants, by frontline healthcare workers (Chen et al. 2021).

Linked to the growth of this industry, different agencies in the public and private sectors have been paying more attention to the increase in the level of active pharmaceutical ingredients (APIs) in the environment (Lees et al. 2016), as well as to user practices (Massoud et al. 2015; Vellinga et al. 2014). This has led to public health concerns, as medicines may have economic and environmental impacts if discarded incorrectly (Bekker et al. 2017; Lees et al. 2016). Active pharmaceutical ingredients (APIs) are omnipresent environmental contaminants created mainly from unused drugs discarded by users in sewers or by healthcare facilities in landfills (Lees et al. 2016; Daughton and Ruhoy 2011).

Furthermore, the presence of chemicals - which frequently are a result of pharmaceutical activities themselvesparticularly in potable water has boosted discussions and debates on the best practices for discarding end-of-use and endof-life medicines (EOU-EOL-M) (Campos et al. 2017; Daughton and Ruhoy 2011; Glassmeyer et al. 2009; Medeiros et al. 2014; Viegas et al. 2019). Explaining, a product is considered in its end-of-life (EOL) when it completes its service life time (Kongar et al. 2015, p.51). End-ofuse (EOU) returns refer to those situations where the user has a return opportunity at a certain life stage of the product (De Brito 2008 p.51)

Despite the reuse of end-of-use medicines would encourage patients to return unused medicines instead of unsafe disposal practices, there is always the risk of the improper storage of unused medicines in terms of the temperature, humidity, or cleanliness of the storage environment. Inadequate storage practices may impact on the safety of unused medicines.

Safety was conceptualized as inadvertent contamination or deliberate tampering (Alhamad et al. 2018). In view of the worldwide transmission situation of COVID-19, the risk is still exacerbated by the possibility of cross-contamination among people infected by the virus, if they were allowed to return their medicines. Apart this discussion, the management of end-of-use and end-of-life medicines calls for reverse flows processes.

Reverse logistics for medicaments has its own particularities if compared to other industries. For example, recycling returned material, which can be a source of income, is a difficult strategy to adopt for pharmaceuticals. That and other particularities make proactive implementation more difficult, as reverse logistics of medicines is limited by external and internal barriers (Murillo-Luna et al. 2011). For example, MurilloLuna et al. (2011) have identified 25 barriers deemed "significant" in 240 industries in Spain: external barriers, endemic limitation in the company, environmental motives, lack of employee training or limited expertise, and inertia in operations. Different authors highlight the greater difficult in implementing reverse logistics due to incertitude on product quantity and quality (Badenhorst 2016; Prakash and Barua 2015; Sirisawat and Kiatcharoenpol 2018) and to the lack of information technology systems (Abahussain et al. 2012; Narayana et al. 2014).

Considering that the use of medicaments is intrinsic to certain chronical treatments, thus their use is inevitable and necessary for individuals' health and well-being, it is essential to understand how different factors affect the effective implementation of reverse logistics (Luthra et al. 2017; Mangla et al. 2016). Moreover, the chronic patient's care must be maintained, along with all the complexity of tasks that the pandemic brings to the pharmaceutical care professionals, such as isolation instructions, safety guidelines, and vaccination. In addition to the complexity of tasks, there is certainly a significant increase in health waste (Medina et al. 2020).

Considering the distinct interests, Alhamad et al. (2018, p. 237) mention that "[...] pharmaceutical companies and their employees (or others with an interest in these companies) were considered amongst the groups that would disapprove medicines reuse because of a potential of reducing financial profits." If in one hand reverse flows of medicines are not 
attractive to pharmaceutical companies, on the other hand, government would take advantage of the savings that the take back of EOU medicines would bring. This would be very attractive at the pharmaceutical care process level managers' point of view, for instance.

Management of medicament processes, including the promotion of their rational use, is called Pharmaceutical Care Process (PCP). Pharmaceutical care process is defined as a set of actions and services that seek to ensure full treatment assistance and promotion, protection, and recovery of health in public and private institutions that undertake pharmaceutical activities; medicaments are the fundamental input, while access to them and their rational use are the purposes (Brasil 2007).

In the context of Brazilian universal public healthcare, which is under study in this research, each municipality is responsible for managing healthcare waste under a reverse logistics chain perspective Pereira et al. (2012). However, the main factors that lead to adopting such practices are proportional to the barriers that exist to it, which leads to a low level of adherence that is rarely discussed in literature and, most importantly, complex in nature (Abdullah and Yaakub 2014).

In Brazil, primary healthcare is the first level of an individual's access to the Universal Healthcare System (Sistema Único de Saúde (SUS)). This health network operates hierarchically: municipal managers are responsible for less complex healthcare with greater demand as it may be accessed by every citizen (Brasil 2007). Municipalities are also responsible for managing the fundamental flow of direct logistics for medicaments in pharmaceutical care process; it is a cutout of the entire process that includes six operations: selection, scheduling, acquisition, storage, distribution, and administration ( $S P A A D D$, in the acronym in Portuguese), named as logistics of pharmaceutical care cycle, from now on in this text. This study emphasizes this set of logistical pharmaceutical care process operations in primary healthcare. Higher complexity levels (secondary, tertiary, and quaternary care) are not in the scope of this research. Thus, in primary healthcare, the last operation in the direct logistics of pharmaceutical care (SPAADD), administration, refers to the delivery of medicaments to the population, free of charge, in government-ran pharmacies, and in health centers.

Operations in the logistics of pharmaceutical care cycle have been implemented and managed based on SUS' management guidelines (Brasil 2007), which means those processes have reached some management maturity, especially in larger cities. However, this maturity has not yet been reached for reverse flows. Returns of EOU-EOL-M drugs from the population are prohibited by Normative Ordinance no. 344, dated May 12, 1998 Brasil. Ministério da Saúde (1998). However, reverse flows of medicaments which are still in good condition happen between pharmacies and health centers and are called "reassignment flows." Even though Law 12.305 and Resolution 222/2018 (Brasil 2018) set forth the implementation of reverse flows, even for the pharmaceutical industry, those flows must be designed for the whole supply chain, including the part pertaining to logistics of pharmaceutical care cycle operations in pharmaceutical care process. For developing countries, which already have financial restrictions, every initiative to reduce costs is welcome.

Therefore, it is relevant to explore which flows refer to reverse logistics of drugs that are still in good condition to be used (EOU) and of drugs that shall be handled are unserviceable (EOL) in pharmaceutical care process context. Therefore, the first research question (RQ1) we seek to answer with this study is:

$R Q 1$ : What medicament reverse logistics flows comprise the pharmaceutical care process accordingly to the experts?

Literature often deals with different sectors and economic, political, social, and cultural contexts - for example, the study by Chauhan et al. (2018), Prakash et al. (2015), and Sharma et al. (2011), which observes the barriers inherent to the Indian context.

Institutions must indistinctively overcome those barriers to effectively adopt RL (Daughton and Ruhoy 2011; Massoud et al. 2015). However, albeit the importance of exploring reverse waste management issues in healthcare, given its importance for the environment, there are few studies dealing with the topic of pharmaceuticals. The number of studies is even smaller regarding PCP logistics in public healthcare.

Considering that the logistics of pharmaceutical care cycle in the PCP cycle also contribute to generating medicine waste and that managers are potentially responsible for dealing with such residue, we propose the following research question, $R Q 2$ :

RQ2: What are the critical factors for undertaking reverse logistics flows for medicines in the context of pharmaceutical care process operations?

The premise under this investigation is that to know the critical factors is a step necessary in overcoming the current restrictions in direction of a well-succeeded medicines reverse logistics in primary healthcare level.

Therefore, this study aims to investigate the most relevant critical factors for implementing medicine waste management in pharmaceutical care process. The unit analysis is health process in a developing country capital. Porto Alegre is the capital of the State of Rio Grande do Sul (Brazil) and has 1.6 million inhabitants who have access to medicines through pharmaceutical care process operations. The Pharmaceutical Care Process Coordination (COORAF, the acronym in 
Portuguese) of the city's Municipal Department of Health manages those operations. The complexity of the process of distributing medicaments may be grasped by the fact that there are 10 government-ran pharmacies and over 140 health centers where healthcare professionals administer pharmaceuticals and offer guidance on how to correctly use them. EOUEOL-M reverse flow from the public that is served by those processes is not yet authorized.

The main academic contribution from this qualitative study is to improve the understanding about critical factors for the implementation of reverse logistics of medicines in pharmaceutical care processes. The practical contribution is to support managers from over 5000 municipalities in Brazil with information that will provide a base for decision-making on how to organize reverse logistics processes in the context of primary health systems.

\section{Theoretical framework}

\section{Reverse logistics of medicaments}

Developing countries around the world face several problems that impact or degrade the environment (Nakyanzi et al. 2010). Managing reverse supply chains is particularly challenging for perishable products (Abbas and Farooquie 2013).

Reverse logistics is part of sustainable development, becoming increasingly important during the last few years. This is a reflex of the search for lower costs, for extracting value from waste in a circular economy, and for environmentally friendly ways of discarding products after consumption (Bernon et al. 2018; Guarnieri et al. 2020; Khan and Subzwari 2009; Prakash et al. 2015).

Conceptually, (Rogers and Tibben-lembke 2001, p. 2) define RL as:

[...] the process of planning, implementing and controlling the efficient, cost-effective flow of raw materials, in-process inventory, finished goods, and related information from the point of consumption to the point of origin for the purpose of recapturing value or of proper disposal.

In Brazil, the National Policy on Solid Waste (Politica Nacional de Resíduos Sólidos (PNSRS)) was established by Law 12.305/2010. It is based on the principle of shared responsibility among the actors of the supply chain aimed at managing waste (Brazilian Policy of Solid Waste 2010).

In general, one of the reasons company managers adopt RL practices at first is to comply with legislation that make manufacturers responsible for products they sell and distribute. However, there are other benefits such as minimizing environmental impacts, saving natural resources, and consumers' inevitable return (Abbas and Farooquie 2018; Prakash et al. 2015).

Alongside other residue generated in healthcare operations in hospitals, clinics, and homes, medicaments are complex waste, as their handling required destructing the active substance (chemical ingredient or drug) (Daughton and Ruhoy 2011; Glassmeyer et al. 2009; Le Corre et al. 2012). Consequently, their discard has been of concern for professionals in public and private healthcare (Aquino et al. 2018; Kelly et al. 2018; Vellinga et al. 2014).

Environmental issues cannot be left aside: it is a wellknown fact that pharmaceutical waste from manufacturing and discarding drugs enter ecosystems, affecting human health (Thach et al. 2013; Tong et al. 2011; Vellinga et al. 2014). Barring residue from ending up in direct contact with nature is a great challenge (Le Corre et al. 2012; Blankenstein and Junior 2018). Despite reverse logistics is part of the systemic PCP, as observed in Fig. 1, currently it is not fully implemented.

There is global awareness that inadequate disposal of medicaments that were not used may harm the environment Braund et al. (2009), especially those originating in industrial activities. Toxicity analyses from the study by Zhou et al. (2018) indicated that some diseases - even cancer - may be linked to exposal to certain chiral pharmaceuticals. Disposal of end-of-use and end-of-life medicines in water also hinders the development of aquatic beings (Bound and Voulvoulis 2005). Furthermore, due to increased consumption by the population, medicine components have been frequently detected in water, which has several consequences for the environment Tewari et al. (2013). However, waste management must be adapted to the involved manufacturers and consumers, as it is highly dependent on economies of scale and requires high levels of cooperation between all the links in the chain Van Der Wiel et al. (2012).

Literature indicates that undertaking reverse logistics practices requires collaborative, economic, technological, and political human structures capable to responding to all the challenges inherent to each industry (Bernon et al. 2018; Mahadevan 2019; Paula et al. 2019). Solid coordination between retailers in different industries and their clients is required to harmonize sales and consumption. Likewise, vertical programs must be in place to avoid duplicated purchases (Nakyanzi et al. 2010).

\section{Critical factors in implementing reverse logistics}

Regardless of the industry under analysis, there are several critical factors in RL implementation. There are those internal of the processes of an institution, while others are external to it. This section will present the following aspects: management factor (MF), collaboration factor (CF), information 


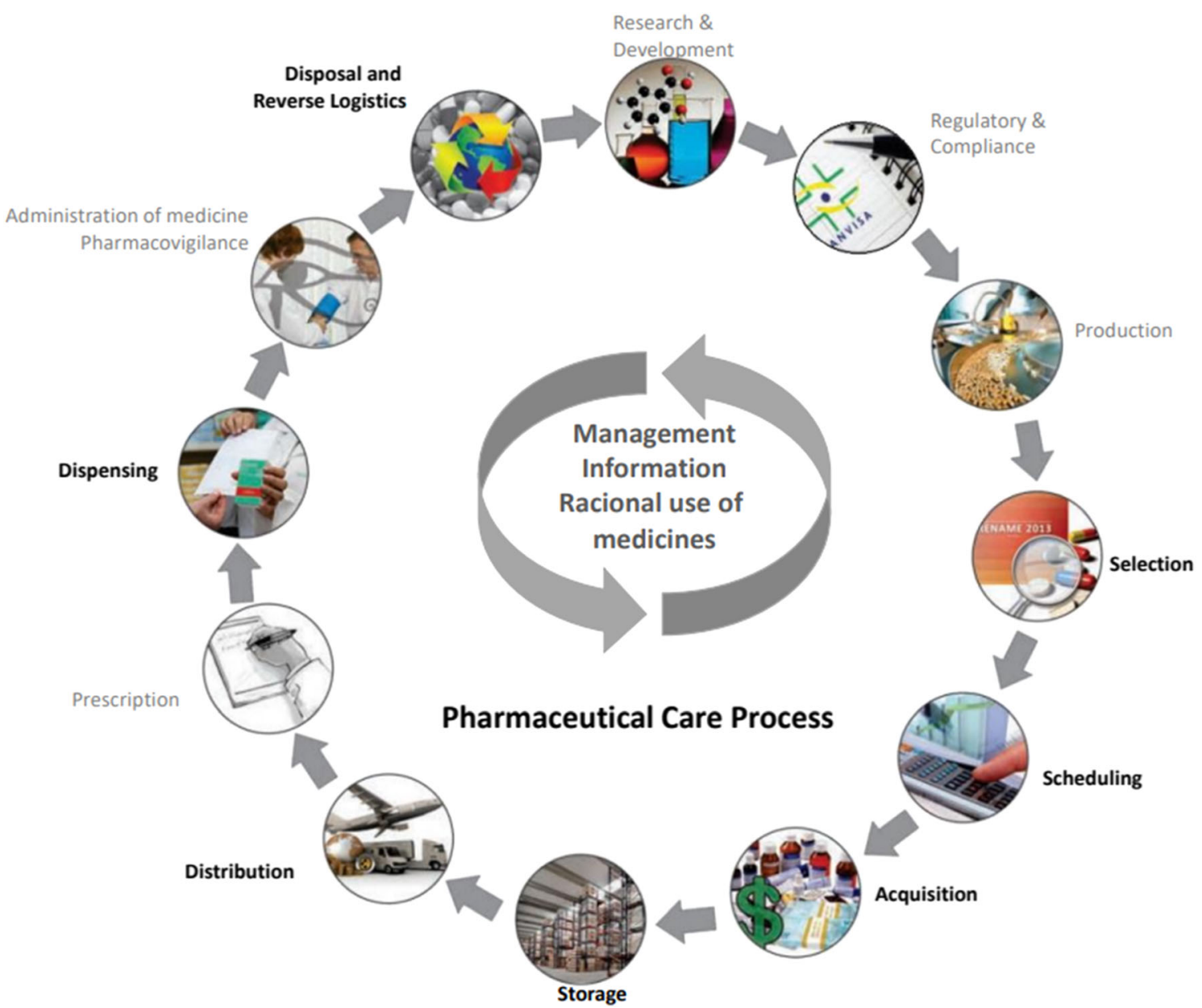

Fig. 1 Pharmaceutical care process operations - in bold the SPAADD cycle operations - adapted from Remondi and Grochocki (2015)

technology factor (ITF), infrastructure factor (IF), political factor $(\mathrm{PF})$, and financial and economic factor (FEF).

\section{Management factor}

The implementation process for reverse logistics in institutions depends on many internal factors, such as the behavior of managers and how they perceive reverse logistics as an integral part of direct logistics (Abdulrahman et al. 2014; Jindal et al. 2013; Ravi et al. 2005). If implementation of reverse logistics is complicated in the private sector, consider it in the public sector. In the public sector, managers are guided by public policies; they maintain a health vision of the population and much more worried about health recovery than by environmental issues. Moreover, managers are restricted by resources and rules that are not very flexible in relation to the use of those same resources.

In private organizations, managers are not only resistant to change; institutions often adopt restrictive policies that lead to lack of environmental awareness (Chileshe et al. 2015; Prakash and Barua 2015). Mathiyazhagan et al. (2014) and Moktadir et al. (2018) also consider commitment from higher management as a barrier. Another relevant issue that may hinder reverse logistics implementation is the lack of human resources and/or qualified workforce available and with the required expertise on reverse logistics (Muduli et al. 2013; Sharma et al. 2011; Shen et al. 2015).

\section{Collaboration factor}

In general, collaboration between the links in the supply chain is discussed regarding direct logistics, as the study by Pakdeechoho and Sukhotu (2018) and Soosay and Hyland (2015). In a systematic literature review, Paula et al. (2019) consider collaboration and trust inseparable elements to implement reverse logistics.

Furthermore, lack of trust may inhibit information sharing, just as lack of communication abilities may hinder the transfer of information. This weakens the commitment to the environment in all levels of organizations, especially if better communication could support them in implementing sustainable activities Bernon et al. (2011).

Information sharing does not mean a company discloses all its information to partner companies. However, it is important 
that participants provide necessary information to each other (Chan 2007).

\section{Information technology factor}

Benefits resulting from the use of information and communication technology are seen in a positive light. However, regarding quality assurance for products returning for recycling or remanufacturing, lack of technology has a significant impact, as important data on those products may be lost (Agarwal et al., 2016; González-Torre et al. 2010; Janse et al. 2010; Kongar et al. 2015; Laribi and Dhouib 2015; Ravi et al. 2005; Sharma et al. 2011; Xia et al. 2015). Furthermore, El Baz et al. (2018); Mathiyazhagan et al. (2014); Jabbour et al. (2016); Jindal et al. (2013); Luthra et al. (2011); and Pumpinyo and Nitivattananon (2014) have reported low data security and even lack of big data that provides more precise information to base decision-making are barriers to reverse logistics implementation.

Traditional measures, such as waste processing technologies that are used to handle hazardous waste, are deemed inadequate to integrate managing, collection, storage, distribution, and transportation activities comprising broad reverse logistics operational strategies Shi et al. (2012).

\section{Infrastructure factor}

Some studies debate the infrastructure required to undertake waste management practices (Cline et al., 2015; Sivakumar et al. 2018). However, infrastructure is often assessed within a technological framework, as mentioned by Erol et al. (2010) and Waqas et al. (2018).

Within the infrastructure factor itself, this study considered aspects pertaining to transport and storage of items intended for reverse logistics processes, as pointed out in previous studies by Abdulrahman et al. (2014); Diabat et al. (2013); and Prakash and Barua (2015). According to Beh et al. (2016), products intended for recycling pose a greater challenge as they are far from their suppliers, resulting in challenges for transportation and complexity for international logistics.

Meyer et al. (2017), in turn, argue that many suppliers do not specialize in transportation and choose cheaper alternatives without considering their possible consequences. According to them, managers frequently subcontract transportation providers whose drives do not understand the stages required for reverse logistics processes, which results in losses.

\section{Political factor}

Among other relevant factors for effective reverse logistics processes in different industries, the political factor plays a major role as action and participation from governments in all levels are required to develop policies and pass legislation that contemplate the particularities of each of those industries. According to Bouzon et al. (2018), issues pertaining to legislation are still not mature in emerging economies such as Brazil. Whenever legislation is flawed or non-existent, legal and political factors may become an external barrier to the implementation of reverse logistics (Abdulrahman et al. 2014).

Rahman and Subramanian (2012) argue that public legislation is one of the main forces driving environmental efforts that managers may or may not adopt. Support from municipal government, for example, allows different sectors, both public and private, as well as industries, to have guidelines on how to return products they produce and distribute.

\section{Financial and economic factor}

Organization managers are often unable to implement RL activities due to the lack of financial resources Ali et al. (2018). Sharma et al. (2011) highlight cost as one of the main challenges for recycling. Economic aspects also affect implementation of improvements to IT systems, as they require more resources, and without them, it is impossible to track and recover products through several processes such as reutilization, remanufacturing, and recycling. Personnel training is also relevant for managing waste and ultimately to make reverse logistics profitable. However, this requires financial support (Sharma et al. 2011).

Economic challenges to adopt waste management practices pertain to circumstances beyond the control of companies, but that affect their priorities, especially concerning the environment. This situation is even worse for companies that are not sure of the value of green practices (Hillary 2004).

\section{Methodology}

\section{Study subject}

The subject for this study was the pharmaceutical care process of the city of Porto Alegre, State of Rio Grande do Sul, Brazil, under the Pharmaceutical Care Process Coordination (COORAF, the acronym in Portuguese). The municipality's public assistance network has ten regional pharmacies and around 140 health centers. It is also responsible for the city's central medicament stock, servicing a population of 1.6 million people. In the context of the public health system, drugs are procured by bidding, based on the Municipal List of Essential Drugs (REMUME). After receiving care, patients present their prescriptions at public pharmacies and health centers, where they receive their medicines free of charge.

After this research was approved by the ethics committee, we collected data from professionals who work with the PCP 
in the city through a semi-structured script seeking to answering the research questions posed by this study (see Appendix A). A selected small group of professionals performs the logistics of pharmaceutical care cycle, the portion of the pharmaceutical care process (Fig. 1) in the city. The distribution of health professions in each phase of the cycle: selection, scheduling, acquisition, storage and distribution is of 2-4 health professionals, excepting the administration phase. The administration phase is performed at 10 pharmacies and 140 health centers where the medication is dispensed to the city population. Therefore, a sample of ten key-participant interviewees, as a whole, were scheduled according to their availability. A detailed description of interviewees profile is provided in "Interviewee profile" section.

At the interview, participants received information about the project and requested to read the "informed consent form," in which they were informed that data would be used for research purposes only. We also requested their authorization to record the interviews, which would allow information obtained in them to be duly transcribed.

Interviews were individual and lasted for about $40 \mathrm{~min}$ each. The script used for the interview was divided into three major sections: $(i)$ characteristics of the respondent and their knowledge on reverse logistics practices and on the National Policy on Solid Waste; (ii) mapping direct and reverse logistics flows; and (iii) identifying what were the factors each interviewee perceived as critical in direct and reverse flow management.

Interviews were recorded and transcribed. Units of meaning emerged from analyzing their contents - especially types of reverse logistics operations that are already in place. Questions from the script were compared internally among respondents and externally to data from studies from academic literature.

\section{Interviewee profile}

The pharmaceutical supply center is where medicaments are stored and distributed, while municipal pharmacies and health centers receive them. To collect qualitative data, eight of the selected key interviewees were directly involved with coordinating different sectors responsible for the logistics of pharmaceutical care cycle operations (SPAADD): health unit (HU), dispensation; DDC/PSC (Drug Distribution Center/ Pharmaceutical Supply Center) storage and distribution; TPC (Therapeutic Pharmacy Commission); MP (municipal pharmacy); and BEC (Bidding Evaluation Committee) programming and acquisition. Two other individuals who did not work at the Municipal Department of Health were also interviewed. They actively participated in the working group (WG) responsible for creating the Healthcare Solid Waste Management Plan for the city of Porto Alegre. One of them was from the Public Urban Cleaning Company and the other from the Health Surveillance Agency. Table 1 shows the profile of the respondents, who received codes from Interv_1 to Interv_10.

All the interviewees had more than 5 years of experience in their expertise area.

\section{Results and discussion}

The interviews with professionals allowed the mapping of the process with the objective of understanding the direct and reverse logistic flows existent in the pharmaceutical care

Table 1 Interviewee profile

\begin{tabular}{|c|c|c|c|}
\hline $\begin{array}{l}\text { Interviewee } \\
\text { code }\end{array}$ & Sector & Gender & Position \\
\hline Interv_001 & HU & Female & Nurse \\
\hline Interv_002 & $\mathrm{PSC} / \mathrm{DDC} / \mathrm{PSC}$ & Male & Coordinator \\
\hline Interv_003 & $\mathrm{DDC} / \mathrm{PSC}$ & Male & Manager/PSC \\
\hline Interv_004 & DDC/PSC & Female & $\begin{array}{l}\text { Manager/Technical Responsible } \\
\text { Pharmacist }\end{array}$ \\
\hline Interv_005 & CTP & Female & $\begin{array}{l}\text { Manager/Technical Responsible } \\
\text { Pharmacist }\end{array}$ \\
\hline Interv_006 & SG & Female & $\begin{array}{l}\text { Manager/Technical Responsible } \\
\text { Pharmacist }\end{array}$ \\
\hline Interv_007 & $\mathrm{BEC}$ & Female & $\begin{array}{l}\text { Manager/Technical Responsible } \\
\text { Pharmacist }\end{array}$ \\
\hline Interv_008 & HU & Female & $\begin{array}{l}\text { Manager/Technical Responsible } \\
\text { Pharmacist }\end{array}$ \\
\hline Interv_009 & Public Urban Cleaning Company & Male & Chemical Engineer \\
\hline Interv_010 & Sanitary Surveillance & Male & Chemical Engineer \\
\hline
\end{tabular}

$H U$ health unit, DDC/PSC Drug Distribution Center/Pharmaceutical Supply Center, TPC Therapeutic Pharmacy Commission, $M P$ municipal pharmacy, BEC Bidding Evaluation Committee 
process. At least two different types of reverse flows were detected: the reverse stock of medicines in the "Reverse logistical flow of stocks of medicines - reassignment logistics" section and the other reverse flow in the "Other types of reverse logistics flows for medicines" section.

\section{Reverse logistical flow of stocks of medicines-reassignment logistics}

The interview analysis revealed a practice of exchange of exceeding stocks of medicines still in condition of use. The reassignment of exceeding stocks of medicines among the pharmacies and health units was called in this text as "reassignment logistics." This is also considered a reverse logistics. Extra stock of medicines in a given health unit or municipal pharmacy is caused by the fact that the citizens are allowed to pick his medicine up in any of the 140 health units or the 10 municipal pharmacies of the city. As some municipal pharmacies are located in the city near urban transportation stations, that makes it easier to the consumer to pick up the medicine in his/her way in direction to work, more than picking it up in the health unit or municipal pharmacy nearest his/her living address. Moreover, some types of medicines are only dispensed in the presence of a pharmacist professional, like antimicrobial medicines and those that act in central nervous system. Pharmacist professionals work only in the ten municipal pharmacies, concentrating the delivery of specific medicines in these sites. The bidding process, that sometimes is very bureaucratic, is another cause of medicine stock shortage or accumulation. Therefore, even considering the monthly medicines stock forecast, it is frequent to have a medicine accumulation in one site or another. The "reassignment logistics" is the best practice developed between health units and municipal pharmacy managers of exchanging products to face the fluctuating demand.

After analyzing the contents of interviews, we were able to identify which flows were included in medicament reassignment logistics between pharmacies and healthcare centers: (a) drug dose to expiration in condition of use; (b) excess medications in use condition (still in condition of use (SCU)); (c) donations; (d) lend of medicines; and (e) exchange.

After transcribing the interviews, we also identified another flow: emergency suitcases or strategic medicines (highlighted in Fig. 2 in a light color). Emergency suitcases or strategic medicines include drugs and other consumables used in emergency situations in health centers. They comprise both medicaments for the treatment of out-patients and controlled, injectable drugs.

As the emergency suitcase was identified at a later stage of our research, it was not included as one of the activities among the critical factors of Figs. 3 and 6. Figure 2 in the sequence details the flows described.

The reassignment flow in Fig. 2 was created together with the interviewees, and they have validated it. It intends to provide a visualization of what they perceive to be the most relevant steps in their effort to avoid medicines to expire as well as to regain value from them.

As stated before, the reverse logistics of end-of-use or endof-life medicines arising from consumers is forbidden. Therefore, to attend the purpose of this study, we have identified critical factors that affect the reassignment reverse logistics. The premise is that the critical factors for reassignment logistics are a glance on the factors that may impact the

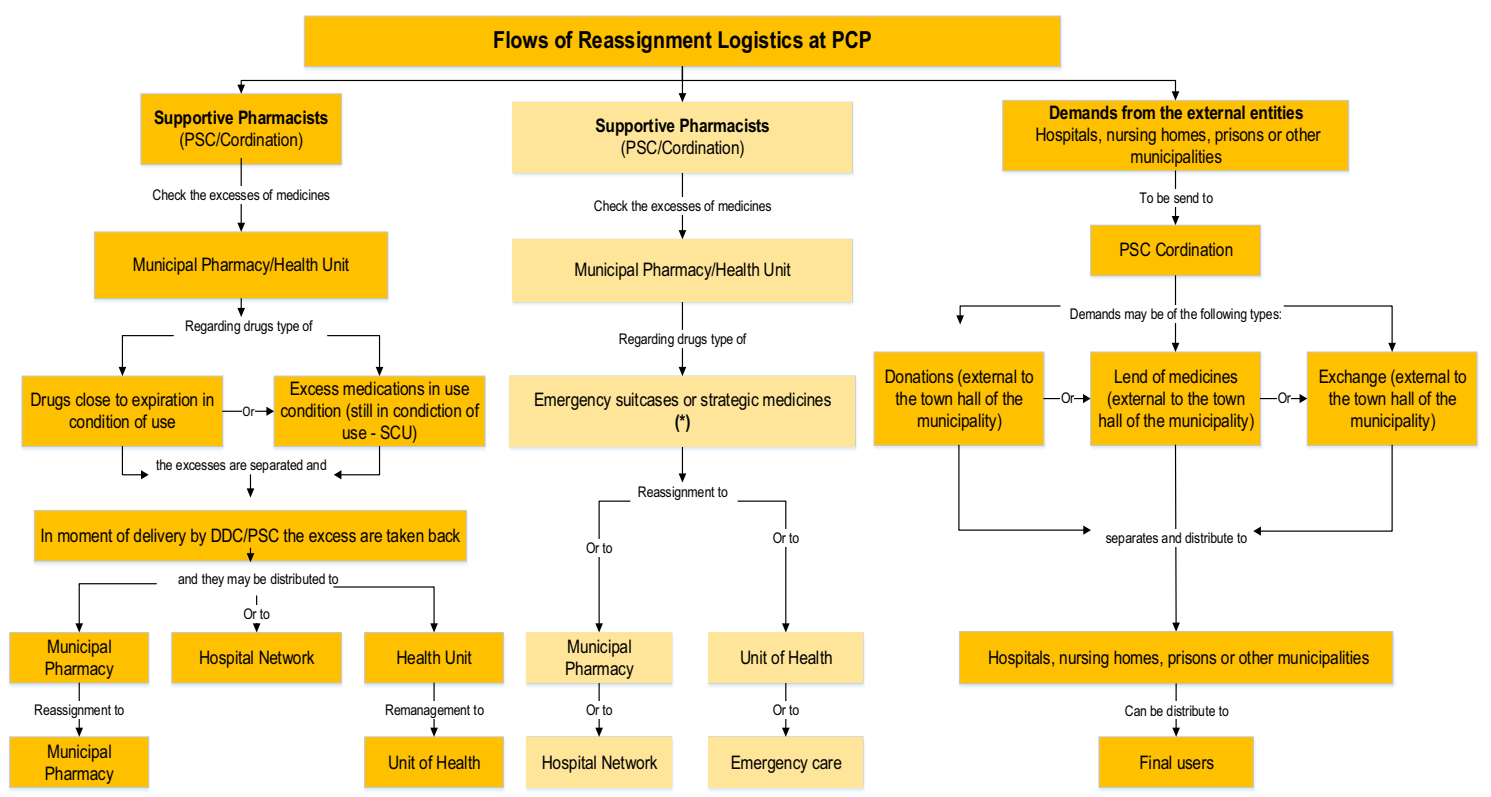

Fig. 2 Flows of reassignment logistics. PCP pharmaceutical care process, PSC pharmaceutical supply chain, DDC Drug Distribution Center. (*) Emergency Suitcases comprise drugs for the treatment of out-patients as well as controlled, injectable drugs 
Fig. 3 Critical factors in reassignment logistics.

Management factor (MF), collaboration factor (CF), information technology factor (ITF), infrastructure factor (IF), political factor $(\mathrm{PF})$, financial and economic factor (FEF)

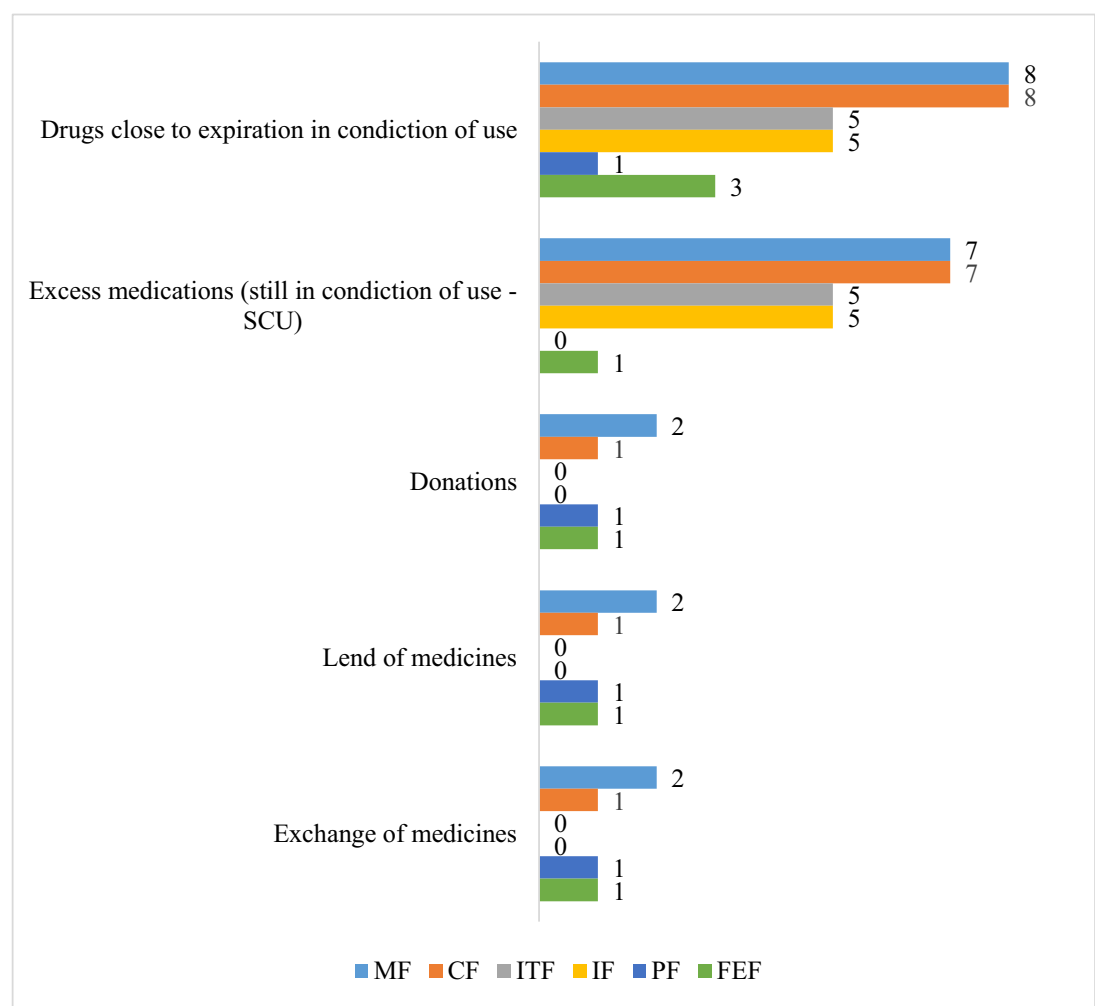

reverse logistics from end users as well. The "Critical factors in the reassignment logistics" section presents critical factors for medicines reassignment logistics.

\section{Critical factors in the reassignment logistics}

Interviewees were shown a list of previously identified critical factors during their interviews about the reassignment logistics of medicines. They could indicate if there was more than one critical factor in each activity in the reassignment logistics flow. Figure 3 presents the frequency of critical factors identified by each interviewee at each stage of reassignment flows.

As we can see on Fig. 3, interviewees considered the management factor and the collaboration factor as the most important for drug reassignment flows. They were identified by 8 out of 10 respondents.

This result is not surprising, since the reassignment flow arises from the collaboration effort among the health units and municipal pharmacies managers. The management factor included aspects pertaining to the number of public civil servants available to undertake those activities, expertise and technical knowledge, worker motivation, and training. This is in line with studies by Ali et al. (2018) and Xia et al. (2015), who affirm that lack of qualified professionals for remanufacturing, lack of support to workers, and lack of personnel training are relevant barriers. Although the practice of "reassignment logistics of medicines" among the sites is much less time-consuming than the "remanufacture of a product" in a typical reverse logistics process, it is expected that every reverse flow is out of the current routine of the pharmaceutical cycle (SPAADD) direct flow. Considering that, the entire infrastructure of the pharmaceutical care process is designed to attend the several activities of the direct flow, it is reasonable that every extra activity exceeds capacity, revealed in voice of interviewees demanding for more "people" for reassignment purposes. The exceeding capacity is also observed in terms of physical space, as demonstrated in Fig. 4.

The collaboration factor includes aspects pertaining to information sharing and exchange, reliability in information exchange, as well as cooperation and collaboration between parties involved in the process. Lack of cooperation was the focus of Mathiyazhagan et al. (2014), but this is not exactly the same cultural problem in the case of the public pharmaceutical care process. Collaboration among the mangers in the public service perhaps is a practice less difficult to be implemented than in the private supply chains of industries. The supposition is due to the fact that health managers of different cycle operations (Fig. 1) are frequently stimulated by Health Ministry trainings to face each other as dependent linkages of the health system process.

The second and the third most relevant critical factor for reassigning excess medicaments that are still in good condition were infrastructure and information technology, which were identified by 5 out of 10 interviewees.

The infrastructure factor includes facilities for storing reassigned medicaments. In fact, the current pharmaceutical 
Fig. 4 Illustration of the storage warehouse at $\mathrm{PCP}$ -

remanagement area close of its space limit

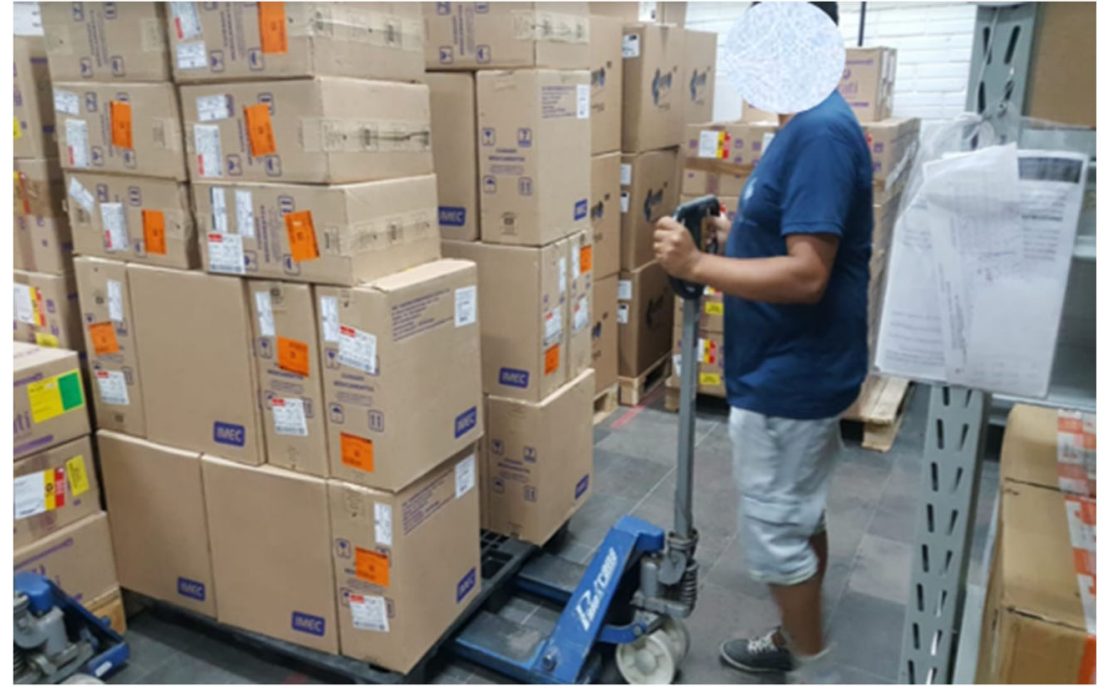

supply chain area available is already accommodating stocks of remanagement, but it is very close of its space limit as demonstrated in Fig. 4. According information from interviewees, a group of researchers from the local Federal University are analyzing the pharmaceutical care layout and processes, viewing the optimization of the infrastructure in the place.

In the reassignment flow for medicines whose expiration date was approaching, but that could still be used, once again the most relevant factors mentioned were the management factor and the collaboration factor. They were identified by 7 out of 10 interviewees. Unsurprisingly, the infrastructure factor also appeared as one of the most relevant, as lack of space in facilities restricts drug storage.

The information technology factor was identified by 5 out of 10 interviewees. It includes aspects pertaining to information systems used to record reassigned medicaments and consumables. The information system currently implemented at healthcare centers has been important to make drug administration for users faster.

According to Gyanendra et al. (2011), the quantity and cost of unused prescribed medicines increases, and they must be discarded. Medicines that are not used are a relevant source of waste in healthcare systems around the world (Toh and Chew 2017). On that issue, a statement by one of the interviewees on the implementation of the information system in healthcare units helps us to understand the importance of the information technology factor in regaining value:

[...] Losses from the number of products lost because they expired multiplied by their unit prices are currently at 19,577 Brazilian reais. However, 223 thousand were recovered by transferring medicaments from places where they would expire to places where they would not. We are able to recover 10 times what we lose.
They expire mostly at health centers. They hardly do at regional pharmacies [resp_002]. 'There are more visits every two months, and at the same time they are reassigned more often, which means they do not expire'. [Interv_002]

Three out of ten interviewees, in turn, identified the financial and economic factor as critical. This factor includes aspects pertaining to financial and economic amounts that could be recovered via reassigned medicaments. In 2018 there was a reorganization of metrics and indicators, and the data collected revealed that a significant amount of money for bidding was saved due to "remanagement" among sites.

For other medicament reassignment flows (donations/loans of medicines/exchange of medicines), critical factors were mentioned less often, by two out of ten interviewees.

\section{Other types of reverse logistics flows for medicines}

By analyzing the content from interviews, we were also able to identify cycles pertaining to other types of reverse logistics: (a) expired medicines delivered by the population; (b) expired medicines from health units; (c) medicines overdue in own stock e; (d) drug for return to supplier; and (e) defective medicine or with breakdown. Figure 5 details the flows described.

The flowchart in Fig. 5 was created together with the interviewees, and they have validated it. It intends to provide a visualization of what they perceive to be the most relevant steps in their effort to avoid medicines to expire, as well as, to regain value from them.

As stated on the purpose of this study, we were able to identify critical factors by analyzing contents from interviews. The "Critical factors in other types of reverse logistics of medicines" section presents critical factors for the reverse logistics of medicaments other than the reassignments logistics 


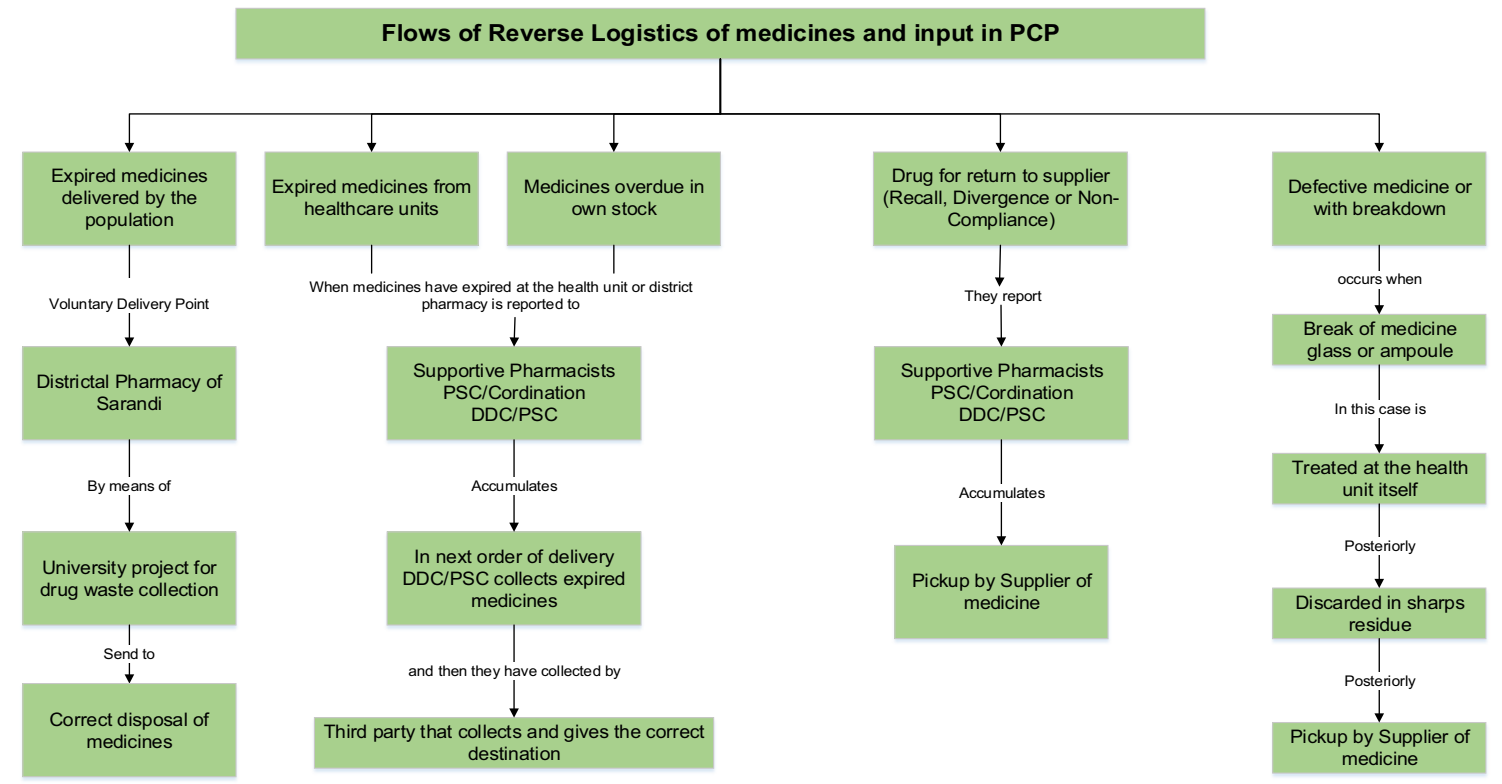

Fig. 5 Flows of reverse logistics of medicines. PCP pharmaceutical care process, PSC pharmaceutical supply chain, DDC Drug Distribution Center

presented in the "Critical factors in the reassignment logistics" section.

\section{Critical factors in other types of reverse logistics of medicines}

As mentioned in the "Critical factors in the reassignment logistics" section, interviewees were shown a list of previously identified critical factors during their interviews about the reverse logistics of medicines. They could indicate if there was more than one critical factor in each activity in the reverse logistics flow of medicaments. Figure 6 shows the frequency of critical factors identified by each interviewee in each step of logistics cycle of pharmaceutical care process.

As we can see on Fig. 6, there is a greater prevalence of critical factors identified by the interviewees in reverse logistics flows, other than the reassignment flow. In the flow for
Fig. 6 Critical factors in reverse logistics. Management factor $(\mathrm{MF})$, collaboration factor $(\mathrm{CF})$, information technology factor (ITF), infrastructure factor (IF), political factor $(\mathrm{PF})$, financial and economic factor (FEF)

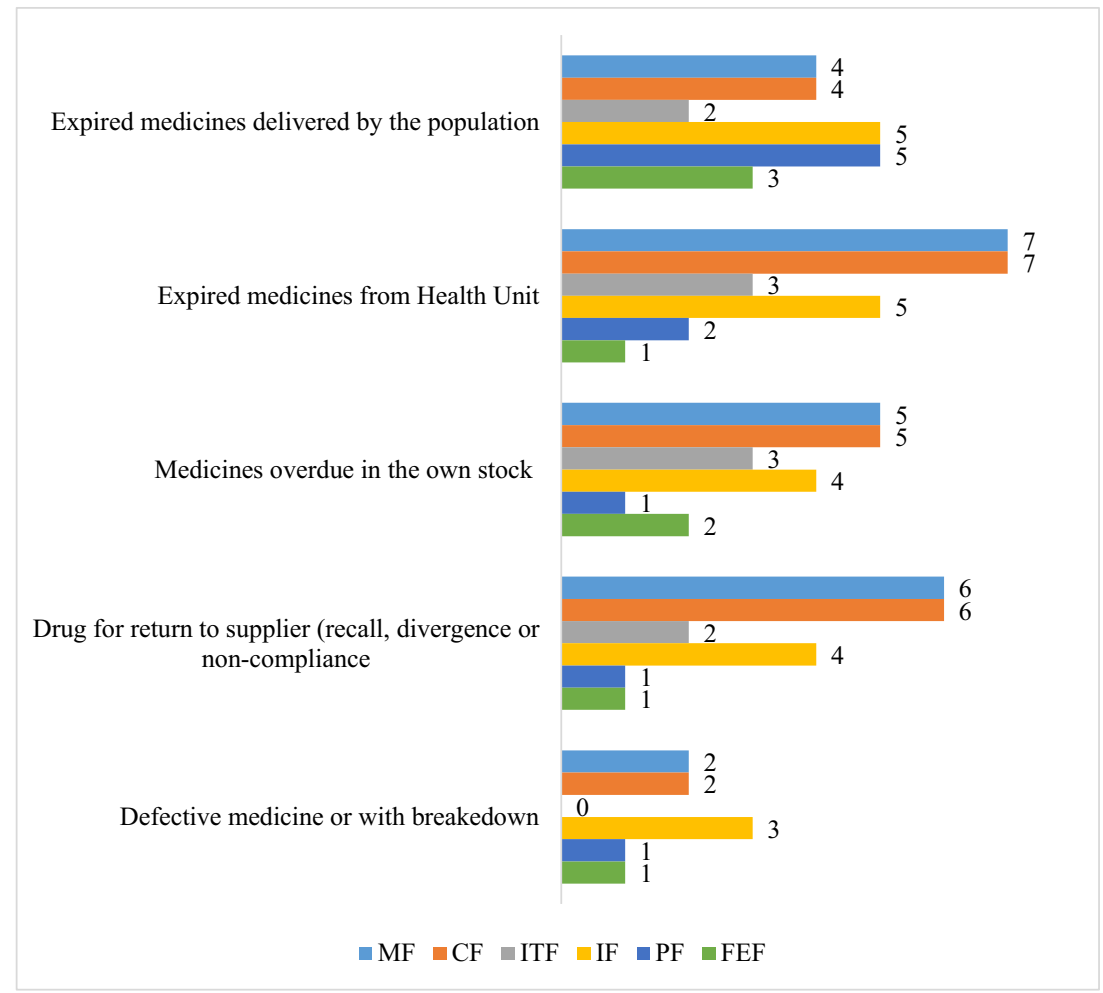


medicines overdue in the own stock, critical factors management factor and collaboration factor were identified by 5 out of 10 respondents each.

We notice that there is an initial concern with the lack of human resources available for administering stocks. This refers to managing drugs that expire while they are the stocks of health centers and pharmacies, as well as to those coming from other healthcare units. This is in line with the results from Glassmeyer et al. (2009) and Sharma et al. (2011). In public institutions, human resources are contracted via public competition what is always dependent on federal, state, or municipal will. Shortage on human resources is not quickly resolved, frequently becoming a chronical problem that managers have to face and administrate in routine. Despite managers at private organizations face a quite different situation, since they would be free to contract human resources to fulfill the needs of reverse logistics implementation, human resources for reverse logistics is a frequent problem mentioned in literature.

The information technology critical factor was mentioned by 3 out of 10 interviewees. Lack of information systems for reverse logistics was also identified by some authors (Jabbour et al. 2016; Laribi and Dhouib 2015; Waqas et al. 2018).

Still concerning infrastructure, we can notice a lack of facilities to store expired drugs and consumables that must be submitted to Drug Distribution Center/Pharmaceutical Supply Center (DDC/PSC). The infrastructure factor was mentioned by 4 out of 10 respondents. Lack of appropriate facilities to handle returns was also identified by Muduli et al. (2013); Shaharudin et al. (2015); and Waqas et al. (2018). Despite the infrastructure is not a factor very critical in reassignment logistics in the context of this city, it could be in the context of other municipalities of the country. Moreover, in the case of end-of-use or end-of-life reverse logistics of medicines arising from end consumers, physical space for storage of returned products would certainly be complicated. The reverse logistics of end-of-use or end-of-life reverse logistics of medicines arising from end consumers deals with large amounts of items, independent on the municipality. The limited storage physical space even for reassignment products was observed in Fig. 4.

In the flow for expired medicine in health units, interviewees indicated the prevalence of the following critical factors: the management factor and the collaboration factor were identified by seven out of ten respondents. The result was the same in reassignment reverse logistics, and it reinforces the criticality of these factors. When questioned about what they understood as a definition of reverse logistics process, one interviewee clearly indicated the need for collaboration to create reverse processes:

Collaborative logistics process to return a logistics distribution process seeking to appropriately handle each item to reduce losses so drugs are adequately available for people. [Interv_002]

We also notice a lack of human resources available to perform those tasks. This is noticeable in a statement by one of the interviewees:

This is a situation in which human resources make all the difference. It's not about reducing costs, on the contrary, you have more people [...] so there is less workload on each of them, less errors, which are different types of errors... If you make an error in the batch or in the quantity, we can fix that because we correct any non-compliance... But what if you give the wrong drug to a patient? [Interv_004]

The next most relevant critical factors were infrastructure, with 5 mentions, and information technology, with 3 mentions. As for medicaments returned by the population, interviewees most often identified the infrastructure and the political factors as critical, which were mentioned five times each. The main purpose of the pharmaceutical care process is to provide medicines to the city population. Due to infrastructure and legal issues, the pharmaceutical care process does not receive back from consumers those two types of medicineexpired and/or in good condition for use. The "Medicines returned by patients" section includes a more thorough discussion on this issue.

Four out of ten respondents identified the management factor and the collaboration factor as critical factors. Next were the financial and economic factor, mentioned by three out of the ten interviewees, and information technology, identified by two out of ten respondents.

In the flow of drugs that are returned to the manufacturer due to recall, the management factor and the collaboration factor were considered critical, identified by six out of ten interviewees. Next were the infrastructure factor, mentioned by four out of the ten interviewees, and information technology, identified by two out of ten respondents. Actually, the combination of these factors seems to be essential in management.

In the flow of defective medicine or with breakdown, the most significant critical factor was infrastructure, identified by three out of ten interviewees. It makes sense, since broken flasks of medicines have to be specially treated attending legal rules that make the traceability of them possible, especially if the drug is controlled (i.e., antibiotics, central system drugs). Therefore, special physical spaces, procedures, and training are necessary. Next, the collaboration factor was mentioned, identified by two out of ten respondents each.

The steps and managers responsible for direct logistics are as follows: (i) Selection, a special commission of health professionals define the list of medicines for the municipality 
population; (ii) Scheduling, COORAF/CAF managers schedule biddings based on consumption history and in services offered; (iii) Acquisition/Procurement, COMEL/CELIC commission managers buy the medicines by bidding processes or judicial orders; and (iv) Storage is accomplished by DDC/ PSC the central unit responsible for storing and distributing the drugs. Pharmacists and health professions focus on providing quality care to patients in municipal pharmacies and health centers, respectively. The other types of reverse logistics activities are performed, in general, only at certain specific sectors, as we can conclude from an answer from one of the interviewees: "[...] Reverse logistics is in place, in general, at the relationship between DDC/PSC, health centers and regional pharmacies, and CAF/COORAF [Interv_002]".

Medicines returned by patients Despite it is legally forbidden, the city population try to return medicines to the municipal pharmacies and health centers, for different reasons, such as death of a patient who was using them, interruption in treatments, new treatments, and other reasons.

When patients seek out a health center or a regional pharmacy to return drugs and find out that is not possible, sometimes they leave the medicines at the healthcare units anyway. This is noticeable in statements by several interviewees:

[...] We instruct the public to discard the drugs in other places, but sometimes they are not able to go somewhere else or refuses to do so. They often leave those drugs at the hallways, in benches, or in the restroom [...]. In those cases, we collect them to make sure they are adequately discarded. However, we do inform the population often adequate places to discard drugs, especially as we do not have appropriate discard recipients at regional pharmacies. To avoid having to reassign them to DDC/PSC, we try to inform the public about some places for discard, such as private drugstores, pharmacy departments in universities, etc. [Interv_008], [Interv_004], [Interv_002], [Interv_005]

This situation is a concrete evidence that the population need an adequate location and appropriate process to discard end-of-use or end-of-life medicines. Currently, as we can see on Fig. 3, only one regional pharmacy collects expired medicine via a partnership with the local Federal University, but it is a kind of research under development. In that case, drugs are collected and correctly discarded. In most cases, patients try to return medicine received from other sources, i.e., drugs not listed among those distributed by the public system (REMUME list). Again, this is evidence of the urgency of developing processes for receiving and treating adequately the used medicines, either from the public or from the private sector.
On the one hand, this shows lack of knowledge by the public, and on the other hand, communication issues between patients and pharmacists, who should inform them on how to correctly proceed if medicaments are not used anymore. According to Braund et al. (2009) and Campos et al. (2017), appropriately educating the public about disposal may minimize eventual impacts on the environment and reduce the excess of medicaments wasted. Saravanan and Manoj (2016) argue that the public is often not aware of the impacts drugs have on the environment. Patients who are aware of those impacts are more likely to seek adequate ways to discard medicaments.

However, when pharmacies refuse to accept unused medicaments, they discourage users from doing so (Tong et al. 2011). According to Abbas and Farooquie (2013), often patients do not know the actual reason why pharmacies and health centers refuse to collect those drugs. On that issue, Glassmeyer et al. (2009) highlight the need for the creation of strategies that include opportunities for users to send or take unused medicines to several collection points, such as pharmacies or other places to be correctly discarded. Campos et al. (2017) and Law et al. (2015), in turn, argue that pharmacists may play an important role in educating patients about adequate use and disposal of medicaments. It is interesting to mention that the authors of the current research have published a former paper on reverse logistics of pharmaceutical products (Campos et al. 2017). The literature analysis revealed that pharmacists are in a good position either to collect unused medications or to educate patients, as mentioned by Guarnieri et al. (2020). Abahussain et al. (2012) reinforce the pharmacist practice and awareness regarding the disposal or returned unused medication by the public. Moreover, Eissen and Backhaus (2011), for instance, present an educational material that corresponds to series of worksheets (online resource) for gaining knowledge about the occurrence, fate, and removal of pharmaceuticals in the environment.

Very often, people dispose of medicines improperly due to lack of clarity about the matter, not aware of actual effects on the environment Pinto et al. (2014). This may be observed in a statement by one of the interviewees:

[...] We normally do not provide that information. However, when they show up saying they will no longer use them, or that the person has died, then we instruct them, provide them with an address where they can donate it. Sometimes there are drugs that are not even on our list. [Interv_006]

There is a drug bank in the city, created with the purpose of receiving non-expired medicaments that for some reason are not used by patients anymore. The banks receive those drugs and then give them to people in need free of charge when they 
seek it. Different studies mention the need to create take-back programs or national collection programs (Gracia-Vásquez et al. 2014; Thach et al. 2013; Pereira et al. 2017). However, this requires a great level of organization, as well as significant time, funding, and human resources commitment (Glassmeyer et al. 2009).

According to Abbas and Farooquie (2013), the process of returning medicaments also faces several barriers throughout the reverse supply chain. Even though it complies with return policy conditions, refusal to accept returned medicaments from clients indicates that there are factors that hinder the appropriate operation of return processes. Clients may decide to discard drugs declared non-returnable by themselves or by those responsible for keeping stock due to being expired or having their integrity compromised.

To Bekker et al. (2017) and McRae et al. (2016), waste is partially unavoidable, but may be reduced by redistributing drugs not used by patients. However, they also indicate that there is no knowledge about stakeholders' opinion on medicine redistribution. Stakeholders consider drug redistribution desirable if implementing this process is viable and if the requirements for safe redistribution are met. Drug redistribution or recycling raises a relevant debate about saving costs and reducing waste. However, safety and product integrity issues generally block healthcare centers to recycle donated drugs (Toh and Chew 2017).

Due to Brazilian sanitary legislation, the public healthcare sector is prohibited from redistributing drugs, as it cannot verify the conditions in which they were stored while patients held them.

\section{Implementing an information technology system to adminis-} ter medicines in healthcare centers In the recent effort to streamline the Brazilian Universal Healthcare System (SUS), there have been initiatives in place to implement a computerized patient care and medicine distribution system in all healthcare centers in cities that participate in the pharmaceutical care process.

Implementation of such system in regional pharmacies and virtually all municipal healthcare centers allowed excess medicaments from one unit to be reassigned to units, which demanded them.

The outcome was positive as it streamlined the process of delivering drugs to patients, but it was also important to monitor and analyze stock in healthcare units. Managers are thus able to monitor their stocks on a daily basis, as may be gathered from a statement by one of the interviewees: "I think implementation of the system was positive [Interv_004].”

The need for improving the system was also noted, to include warning systems for expiration dates, which would make it easier for managers to see in the system itself what drugs are close to expiring:
[...] We actually have the system in place here, which does not have a warning (a popup saying 'they will expire in one month'), but it does monitor them and allow you to monitor them as well. [Interv_004]

Advancements in technology must be considered in creating and reviewing disposal routines. It is also relevant to understand and disclose factors that lead to certain principles being adopted. This information helps decision-makers (Nakyanzi et al. 2010; He et al. 2016). This may be observed in a statement by one of the interviewees:

[...] By implementing the DIS (administration system) in healthcare units, we received may drugs that could still be used and that were expiring soon. [Interv_006]

After a system allowing precise information pertaining to quantity in stock was implemented, drugs could be reassigned, as the other types of reverse logistics of medicines. Then, all stock was audited by supporting pharmacists and included in the system, which started operating drug administration activities exclusively via a computerized system.

Supporting pharmacists Another point that came up during the interviews was the fundamental role played by supporting pharmacists, who have been working effectively in managing and in implementing drug administration practices via the computerized system. The PCP currently has three supporting pharmacists who support the whole system. This may be observed in statements by the interviewees:

There should be more pharmacists that could offer support to units more often [...] the number of pharmacists for those support tasks is too small and way less than what we actually need. [Interv_008]

Additionally, the role of supporting pharmacists is important to avoid expiration of medicaments at healthcare centers without reassigning them to other units to avoid losses:

[...] that change had a significant impact in the last few months, and we can see the volume has decreased... because the drugs were not administered, so I was not going to ask for them anyhow, as before. So, I think this will happen less often [Inter_004]. 'In-loco visits cannot stop happening in places that have been visited or where the DIS was implemented, as there are still excess drugs. Currently, the system does not show who transferred the most. Places visited by supporting pharmacists return drugs. We still have problems with the car used for those 
visits [...] currently it is cheaper to employ a driver than letting drugs expire'. [Interv_002]

Drug backlog or undesired left-over drugs result in three major concerns: (i) individual protection equipment (IPEs) discarded in sewers or in the garbage, which are a complex source of potential chemical release to the environment; (ii) drug backlog presents a greater potential of being unduly diverted, risking poisoning and non-intentional abuse; and (iii) drug backlog is also a waste of health resources and represents lost opportunities of medical treatment (Ruhoy and Daughton 2008).

Waste sorting practices Inadequate storage, use, and/or disposal of medicines lead to public health concerns, especially for returned drugs. Healthcare professionals must deal with user misconception about keeping, storing, and discarding them (Kelly et al. 2018). On that subject, a statement by one of the interviewees shows the concern for adequate temporary storage areas for medicaments:

We do not have a separate place for that, they are left in boxes labeled 'expired'. [Interv_008]

[...] If they expire, healthcare units sort them and informs a supporting pharmacist, who then informs DDC/PSC. In the next delivery it collects those drugs, which means drugs accumulate at DDC/PSC. Once a year, a contracted company collects them from health centers and regional pharmacies. When the car delivers the drugs, if the unit has excess or expired medicine, instead of having 140 drug collection points as intended, we centralize collection by another organ in distribution centers. [Interv_002]

As for infrastructure to store expired drugs and consumables destined to be collected by third parties, all interviewees mentioned those drugs are left in a common area where nonexpired drugs to be administered to patients are also kept. Lack of facilities in some units means storage is in a common place until expired drugs are sent to DDC/PSC:

[...] Consumables that cannot be used, such as broken ampoules or glasses, for example, are handled by the healthcare unit itself. They are discarded as sharp residue, just like bottles of injectable dipyrone. I cannot carry something broken in a box for other people to handle. [Interv_002]

Lack of an industry-wide agreement for reverse logistics of medicaments causes environmental and economic issues that pose great challenges for public healthcare in several Brazilian municipalities (Pereira et al. 2017).

\section{Final remarks}

The motivation of this study lies on the qualification of the pharmaceutical care process, since the primary healthcare system is the entrance door to the entire health system. Improvements in this process tend to bring quality to the entire system, since it may reduce costs and prevent diseases, making the system more efficient and effective in the higher levels of complexity (hospital and more complex health services, for instance). Concerning on reverse logistics is part of this effort, since it is not fully implemented. Firstly, the investigation revealed that in terms of pharmaceutical care process, there are different types of reverse flows: the reassignment flow and reverse logistics flow. The reassignment flow is reversed, takes place with the objective of reducing costs and saving medicines that are unused in a specific municipal pharmacy or health unit. The case studied has demonstrated that this is a cleaver strategy that should be incorporated in each of the 5000 municipalities that perform the logistics of pharmaceutical care cycle. Although the study was performed in the city of Porto Alegre, State of Rio Grande do Sul, Brazil, it may reflect the reality in all municipalities of the country. There is an uniformity of practices determined by the Ministry of Health inside the programs from Universal Healthcare System (SUS). The Ministry of Health in Brazil determines that all municipalities have to perform the logistic cycle of pharmaceutical care process and define guidelines for standardization. Considering that, this study indicates that collaboration and information sharing is central. The use of proper information technology is also relevant. The experience of improving information technology systems has proven to bring much more efficiency and reduction of costs in the case studied. Therefore, the first contribution of results is the wide reinforcement and professionalization of reassignment flow of medicines among pharmacies and health centers, at the pharmaceutical care logistic cycle in Brazilian cities.

The study also revealed that, reverse flows of medicines from the end users/consumers actually happen, despite it is not legally authorized in the country. This is evidence of urgency for the authorities to address the problem in search of a solution. The main contribution of this research, in this regard, is the analysis of the barriers that must be overcome in direction to a formal further reverse logistics.

Barriers to reverse logistics were named by interviewees. The political barriers and the complexity of the primary health system, resulting from this investigation, point to further development of a specific management business unit to perform reverse logistics of end-of-use medicines arising from consumers. The population usually try to take back not only the end-of-life/end-of-use medicines that were dispensed by public services, but also the medicines they acquired from the private health services. Therefore, the development of a 
new management unit with specific infrastructure, personal, rules, education, and training would be necessary.

By means of qualitative analysis of data collected from interviews, this case study on primary health system level provided relevant insights for the public health sector as we were able to identify reassignment and reverse logistics flows that were not identified before.

Once activities comprising each flow were identified and verified by managers, we were able to identify their most relevant critical factors. From interviews, we observed the fundamental role played by the implementation of a computerized system for medicine administration in healthcare units throughout the city in those two cases. These medicaments can now be reassigned to other units with greater demand for them, avoiding their expiration. Another fundamental point raised in this study was the role played by supporting pharmacists in the context of PCP.

Finally, partnerships with the University have been positive. Not only it does provide scientific support for projects, but it also encourages research, data collection on medicine disposal, demand, and costs, as well as on the reasons for disposal. It also adequately disposes of returned drugs and consumables.

There is still no pharmaceutical industry-wide agreement in Brazil - as is the case for packaging, for example, which provides guidelines for that industry (Guarnieri et al. 2020). As is the case for other Brazilian municipalities, the city of Porto Alegre faces several challenges in implementing reverse logistics. In light of that, each Brazilian municipality, together with teams from different healthcare sectors, can use Porto Alegre's solid waste management plan, set forth in accordance with Law 12.305 and Resolution 222/2018 (Brasil 2018), as a reference. That legislation categorizes waste generated by the public healthcare sector in groups A to E, listed on the annexes to Resolution 222/2018. Medicines are listed in group B, biohazard waste, which leads those teams to put greater efforts in creating health solid waste management programs.

The most relevant contribution from this study was showing-via a case study of the public healthcare system - the main flows and critical factors identified in each stage of those reassignment and reverse logistics flows, which sheds light on a sector that the literature has only marginally discussed.

The research allowed us to identify the factors such as management, collaboration, information technology, and infrastructure as critical in the following flows: drugs close to expiration in condition of use and medications in use conditions (still in conditions of use (SCU)) in reassignment logistics.

As for reverse logistics of medicaments, the factors most often mentioned by interviewees were management, collaboration, infrastructure, and political. Results from this qualitative study are important for pharmaceutical care processes managers' decision-making and for improving current waste management practices, as managers may develop strategies based on them.

As suggestions for future studies, these results could be quantitatively validated with the use of statistics and multicriteria approach methods to confirm or refute them.

Supplementary Information The online version contains supplementary material available at https://doi.org/10.1007/s11356-021-14661-4.

Author contribution Elaine Aparecida Regiani de Campos (author 1 and corresponding author): conceptualization, formal analysis, methodology, and writing - review and editing

Carla Schwengber ten Caten (author 2): project administration, supervision, visualization, review, investigation, and resources

Istefani Carísio de Paula (author 3): project administration, supervision, and writing - review and editing

Funding This research was funded by the Brazilian Ministry of Education-Coordenação de Aperfeiçoamento de Pessoal de Nível Superior (CAPES) process no. 88882.346482/2.019-01.

\section{Availability of data and materials}

All data used are presented in the body of the text, and the questionnaire used can be accessed as a complementary document.

\section{Declarations}

Ethics approval and consent to participate This study was approved by the Research Ethics Committee, Federal University of Rio Grande do Sul, and Municipal Health Department under number CAAE 82571018.6.0000.5347 and opinion no. 2.532.199 and opinion no. 3.260.151. It was conducted in the Pharmaceutical Assistance (PA) cycle that is under the Pharmaceutical Assistance Coordination (PAC) in the City of Porto Alegre, Brazil. (i) Consolidated Opinion of the Research Ethics Committee (CEP); (ii) Consolidated Opinion of the Research Ethics Committee (CEP)-Amendment.

Consent for publication Not applicable

Competing interests The authors declare no competing interests.

\section{References}

Abahussain E, Waheedi M, Koshy S (2012) Practice, awareness and opinion of pharmacists toward disposal of unwanted medications in Kuwait. Saudi Pharmaceutical Journal 20(3):195-201. https:// doi.org/10.1016/j.jsps.2012.04.001

Abbas H, Farooquie JA (2013) Return and disposal of unused medicines: a customer perspective of reverse logistics. International Journal of Business and Management Invention 2(11):2319-8028 Retrieved from www.ijbmi.org

Abbas H, Farooquie JA (2018) Reverse logistics operations in a pharmaceutical retail environment. Int $J$ Logistics Economics and Globalisation 7(1):1-12

Abdullah N, Yaakub S (2014) Reverse logistics: pressure for adoption and the impact on firm's performance. International Journal of Business and Society 15 
Abdulrahman MD, Gunasekaran A, Subramanian N (2014) Critical barriers in implementing reverse logistics in the Chinese manufacturing sectors. Int J Prod Econ 147(PART B):460-471. https://doi.org/10. 1016/j.ijpe.2012.08.003

Agarwal V, Govindan K, Darbari JD, Jha PC (2016) An optimization model for sustainable solutions towards implementation of reverse logistics under collaborative framework. Int J Syst Assur Eng Manag 7(4):480-487. https://doi.org/10.1007/s13198-016-0486-3

Aksoylu S, Demirel N (2018) Application of activity based costing in reverse logistics environment: a case of end-of-life vehicle recovery in Turkey. Journal of Business Research - Turk 10(4):953-973. https://doi.org/10.20491/isarder.2018.557

Alhamad H, Patel N, Donyai P (2018) How do people conceptualise the reuse of medicines? An interview study. Int J Pharm Pract 26(3): 232-241. https://doi.org/10.1111/ijpp.12391

Ali SM, Arafin A, Moktadir MA, Rahman T, Zahan N (2018) Barriers to reverse logistics in the computer supply chain using interpretive structural model. Glob J Flex Syst Manag 19(s1):53-68. https:// doi.org/10.1007/s40171-017-0176-2

Aquino S, Spina GA, Antonietta M (2018) Reverse logistics of postconsumer medicines : the roles and knowledge of pharmacists in the municipality of São Paulo. Brazil Sustainability 10. https://doi.org/ $10.3390 /$ su10114134

Badenhorst A (2016) Prioritising the implementation of practices to overcome operational barriers in reverse logistics. Journal of Transport and Supply Chain Management 10(1):a240. https://doi.org/10.4102/ jtscm.v10i1.240

Beh LS, Ghobadian A, He Q, Gallear D, O'Regan N (2016) Second-life retailing: a reverse supply chain perspective. Supply Chain Manag 21(2):259-272. https://doi.org/10.1108/SCM-07-2015-0296

Bekker CL, Gardarsdottir H, Egberts TCG, Bouvy ML, van den Bemt BJF (2017) Redispensing of medicines unused by patients: a qualitative study among stakeholders. Int J Clin Pharm 39(1):196-204. https://doi.org/10.1007/s11096-017-0424-8

Bernon M, Rossi S, Cullen J (2011) Retail reverse logistics: a call and grounding framework for research. Int J Phys Distrib Logist Manag 41:484-510. https://doi.org/10.1108/09600031111138835

Bernon M, Tjahjono B, Ripanti EF (2018) Aligning retail reverse logistics practice with circular economy values: an exploratory framework. Prod Plan Control 29(6):483-497. https://doi.org/10.1080/ 09537287.2018.1449266

Blankenstein GMP, Junior AP (2018) The disposal of medicines and the Brazilian National Solid Waste Policy: a motivation for the review of health standards. Revista de Direito Sanitario 19(1):50-74. https://doi.org/10.11606/issn.2316-9044.v19i1p50-74

Bound JP, Voulvoulis N (2005) Household disposal of pharmaceuticals as a pathway for aquatic contamination in the United Kingdom. Environ Health Perspect 113(12):1705-1711. https://doi.org/10. 1289/ehp. 8315

Bouzon M, Govindan K, Taboada CM (2018) Evaluating barriers for reverse logistics implementation under a multiple stakeholders' perspective analysis using grey decision making approach. Resour Conserv Recycl 128:315-335. https://doi.org/10.1016/j.resconrec. 2016.11.022

Brasil (2007) Assistência Farmacêutica no SUS. Conselho Nacional de Secretários de Saúde. - Brasília/DF: CONASS. Retrieved from http://bvsms.saude.gov.br/bvs/publicacoes/colec_progestores_ livro7.pdf

Brasil (2018) Agência Nacional de Vigilância Sanitária. Resolução da Diretoria Colegiada - RDC no 222, de 28 de março de Diário Oficial [da República Federativa do Brasil] §. Brazil: http://portal. anvisa.gov.br/documents/10181/3427425/RDC_222_2018_.pdf/ c5d3081d-b331-4626-8448-c9aa426ec410. https://doi.org/10.1016/ j.jhep.2007.05.013,

Brasil. Ministério da Saúde (1998) Portaria SVS/MS n 344, de 12 de maio, 65 § (1998). Brasília, DF : [s.n]. https://doi.org/http://bvsms. saude.gov.br/bvs/saudelegis/svs/1998/prt0344_12_05_1998_rep. html

Braund R, Peake BM, Shieffelbien L (2009) Disposal practices for unused medications in New Zealand. Environ Int 35(6):952-955. https://doi.org/10.1016/j.envint.2009.04.003

Brazilian Policy of Solid Waste (2010) Law 12,305, August 2nd 2010., Pub. L. No. 12,305 August 2nd. Brazil. http://www.planalto.gov.br/ ccivil 03/ ato2007-2010/2010/lei/112305.htm. (Accessed September 2018)

Campos EAR, Paula IC, Pagani RN, Guarnieri P (2017) Reverse logistics for the end-of-life and end-of-use products in the pharmaceutical industry: a systematic literature review. Supply Chain Manag 22(4):375-392. https://doi.org/10.1108/SCM-01-2017-0040

Chan HK (2007) A pro-active and collaborative approach to reverse logistics - a case study. Prod Plan Control 18(4):350-360. https:// doi.org/10.1080/09537280701318736

Chauhan A, Singh A, Jharkharia S (2018) An interpretive structural modeling (ISM) and decision-making trail and evaluation laboratory (DEMATEL) method approach for the analysis of barriers of waste recycling in India. J Air Waste Manage Assoc 68(2):100-110. https://doi.org/10.1080/10962247.2016.1249441

Chen C, Chen J, Fang R, Ye F, Yang Z, Wang Z, Tan W (2021) What medical waste management system may cope with COVID-19 pandemic: lessons from Wuhan. Resour Conserv Recycl 170:105600

Chileshe N, Rameezdeen R, Hosseini MR (2015) Barriers to implementing reverse logistics in South Australian construction organisations. Supply Chain Manag 20(2):179-204. https://doi.org/ 10.1108/SCM-10-2014-0325

Cline A, LeMay S, Helms MM (2015) A framework for reverse logistics: the case of post-consumer carpet in the US. Int J Commer Manag 25(4):466-489. https://doi.org/10.1108/IJCoMA-02-2013-0013

Daughton CG, Ruhoy IS (2011) Green pharmacy and pharmEcovigilance: prescribing and the planet. Expert Rev Clin Pharmacol 4(2):211-232. https://doi.org/10.1586/ecp.11.6

De Brito, M.P (2008) "Managing reverse logistics or reversing logistics management?", ERIM PhD thesis Series Research in Management, Erasmus Research Institute of Management (ERIM) Erasmus University Rotterdam 327

Diabat A, Khreishah A, Kannan G, Panikar V, Gunasekaran A (2013) Benchmarking the interactions among barriers in third-party logistics implementation: an ISM approach. Benchmarking 20(6):805824. https://doi.org/10.1108/BIJ-04-2013-0039

Ding B (2018) Pharma Industry 4.0: Literature review and research opportunities in sustainable pharmaceutical supply chains. Process Saf Environ Prot 119:115-130. https://doi.org/10.1016/j.psep.2018.06. 031

El Baz J, Frei R, Laguir I (2018) Reverse supply chain practices in developing countries: the case of Morocco. J Manuf Technol Manag 29(1):198-216. https://doi.org/10.1108/JMTM-04-2017-0068

Erol I, Velioğlu MN, Șerifoğlu FS, Büyüközkan G, Aras N, Çakar ND, Korugan A (2010) Exploring reverse supply chain management practices in Turkey. Supply Chain Manag 15(1):43-54. https://doi. org/10.1108/13598541011018111

Fischer A, Pascucci S (2017) Institutional incentives in circular economy transition: the case of material use in the Dutch textile industry. J Clean Prod 155:17-32. https://doi.org/10.1016/j.jclepro.2016.12. 038

Geethan KAV, Jose S, Sunil Chandar C (2011) Methodology for performance evaluation of reverse supply chain. International Journal of Engineering and Technology 3(3):213-224

Glassmeyer ST, Hinchey EK, Boehme SE, Daughton CG, Ruhoy IS, Conerly O, Daniels RL, Lauer L, McCarthy M, Nettesheim TG, Sykes K, Thompson VG (2009) Disposal practices for unwanted residential medications in the United States. Environ Int 35(3): 566-572. https://doi.org/10.1016/j.envint.2008.10.007 
González-Torre et al (2010) Barriers to the implementation of environmentally oriented reverse logistics : evidence from the automotive industry sector, $21 \S \mathrm{https}: / /$ doi.org/10.1111/j.1467-8551.2009. 00655.x

Gracia-Vásquez SL, Ramírez-Lara E, Camacho-Mora IA, CantúCárdenas LG, Gracia-Vásquez YA, Esquivel-Ferriño PC, Ramírez-Cabrera MA, Gonzalez-Barranco P (2014) An analysis of unused and expired medications in Mexican households. Int J Clin Pharm 37(1):121-126. https://doi.org/10.1007/s11096-014-0048-1

Guarnieri P, Cerqueira-streit JA, Batista LC (2020) Reverse logistics and the sectoral agreement of packaging industry in Brazil towards a transition to circular economy. Resour Conserv Recycl 153: 104541. https://doi.org/10.1016/j.resconrec.2019.104541

Hillary R (2004) Environmental management systems and the smaller enterprise. J Clean Prod 12(6):561-569. https://doi.org/10.1016/j. jclepro.2003.08.006

Jabbour CJC, De Sousa Jabbour ABL, Govindan K, De Freitas TP, Soubihia DF, Kannan D, Latan H (2016) Barriers to the adoption of green operational practices at Brazilian companies: effects on green and operational performance. Int J Prod Res 54(10):30423058. https://doi.org/10.1080/00207543.2016.1154997

Janse B, Schuur P, Brito MPDe (2010) A reverse logistics diagnostic tool : the case of the consumer electronics industry, 495-513. https://doi. org/10.1007/s00170-009-2333-z

Jindal S, Jindal A, Sangwan KS (2013) Development of an interpretive structural model of drivers for reverse logistics implementation in Indian industry. International Journal of Business Performance and Supply Chain Modelling 5(4):325. https://doi.org/10.1504/ IJBPSCM.2013.058201

Kabir MI (2013) Reverse logistics in pharmaceutical industry. International Journal of Supply Chain Management 2(1):96-100 Retrieved from http://excelingtech.co.uk/

Kelly F, Mcmillan S, Spinks J, Bettington E, Wheeler AJ (2018) 'You don't throw these things out :' an exploration of medicines retention and disposal practices in Australian homes. BMC Public Health 18(1026):1-12

Khan A, Subzwari M (2009) Reverse logistics in Pakistan's pharmaceutical sector. South Asian Journal of Management Sciences 3(1):2736

Kongar E, Haznedaroglu E, Abdelghany O, Bahtiyar MO (2015) A novel IT infrastructure for reverse logistics operations of end-of-life pharmaceutical products. Inf Technol Manag 16(1):51-65. https://doi. org/10.1007/s10799-014-0195-Z

Laribi L, Dhouib D (2015) Barriers to implementing reverse logistics in Tunisian companies. 10th IEEE Int Conf on Service Operations and Logistics, and Informatics, SOLI 2015 - In Conjunction with ICT4ALL:145-153. https://doi.org/10.1109/SOLI.2015.7367609

Law AV, Sakharkar P, Zargarzadeh A, Tai BWB, Hess K, Hata M, Mireles R, Ha C, Park TJ (2015) Taking stock of medication wastage: Unused medications in US households. Res Soc Adm Pharm 11(4):571-578. https://doi.org/10.1016/j.sapharm.2014.10.003

Le Corre KS, Ort C, Kateley D, Allen B, Escher BI, Keller J (2012) Consumption-based approach for assessing the contribution of hospitals towards the load of pharmaceutical residues in municipal wastewater. Environ Int 45(1):99-111. https://doi.org/10.1016/j. envint.2012.03.008

Lees K, Fitzsimons M, Snape J, Tappin A, Comber S (2016) Pharmaceuticals in soils of lower income countries: physicochemical fate and risks from wastewater irrigation. Environ Int 94: 712-723. https://doi.org/10.1016/j.envint.2016.06.018

Luthra S, Kumar V, Kumar S, Haleem A (2011) Barriers to implement green supply chain management in automobile industry using interpretive structural modeling technique-an Indian perspective. Journal of Industrial Engineering and Management 4(2):231-257. https:// doi.org/10.3926/jiem.2011.v4n2.p231-257
Luthra S, Mangla SK, Kumar S, Garg D, Haleem A (2017) Identify and prioritise the critical factors in implementing the reverse logistics practices: a case of Indian auto component manufacturer. Int J Bus Syst Res 11(1/2):42. https://doi.org/10.1504/IJBSR.2017.080834

Mahadevan K (2019) Collaboration in reverse: a conceptual framework for reverse logistics operations. Int J Product Perform Manag 68(2): 482-504. https://doi.org/10.1108/IJPPM-10-2017-0247

Mangla SK, Govindan K, Luthra S (2016) Critical success factors for reverse logistics in Indian industries: a structural model. J Clean Prod 129:608-621. https://doi.org/10.1016/j.jclepro.2016.03.124

Massoud MA, Makarem N, Ramadan W, Nakkash R (2015) Environmental management practices in the Lebanese pharmaceutical industries: implementation strategies and challenges. Environ Monit Assess 187(3):107. https://doi.org/10.1007/s10661-0154290-3

Massoud MA, Chami G, Al-Hindi M, Alameddine I (2016) Assessment of household disposal of pharmaceuticals in Lebanon: management options to protect water quality and public health. Environ Manag 57(5):1125-1137. https://doi.org/10.1007/s00267-016-0666-6

Mathiyazhagan K, Govindan K, Noorul Haq A (2014) Pressure analysis for green supply chain management implementation in Indian industries using analytic hierarchy process. Int J Prod Res 52(1):188202. https://doi.org/10.1080/00207543.2013.831190

McRae D, Allman M, James D (2016) The redistribution of medicines: could it become a reality? Int J Pharm Pract 24(6):411-418. https:/ doi.org/10.1111/ijpp. 12275

Medeiros MSG, Moreira LMF, Lopes CCGO (2014) Descarte de medicamentos: Programas de recolhimento e novos desafios. Revista de Ciencias Farmaceuticas Basica e Aplicada 35(4):651662

Medina MG, Giovanella L, Bousquat A, Mendonça MHMD, Aquino R (2020) Atenção primária à saúde em tempos de COVID-19: o que fazer? Cadernos de Saúde Pública 36:e00149720

Meyer A, Niemann W, Mackenzie J, Lombaard J (2017) Drivers and barriers of reverse logistics practices: a study of large grocery retailers in South Africa. Journal of Transport and Supply Chain Management 11:1-16. https://doi.org/10.4102/jtscm.v11i0.323

Moktadir A, Mithun S, Rajesh R, Kumar S (2018) Modeling the interrelationships among barriers to sustainable supply chain management in leather industry. J Clean Prod 181:631-651. https://doi.org/10. 1016/j.jclepro.2018.01.245

Muduli K, Govindan K, Barve A, Geng Y (2013) Barriers to green supply chain management in Indian mining industries: a graph theoretic approach. J Clean Prod 47:335-344. https://doi.org/10.1016/j. jclepro.2012.10.030

Murillo-Luna JL, Garcés-Ayerbe C, Rivera-Torres P (2011) Barriers to the adoption of proactive environmental strategies. J Clean Prod 19(13):1417-1425. https://doi.org/10.1016/j.jclepro.2011.05.005

Nakyanzi JK, Kitutu FE, Oria H, Kamba PF (2010) Expiry of medicines in supply outlets in Uganda. Bull World Health Organ 88(2):154 158. https://doi.org/10.2471/BLT.08.057471

Narayana SA, Elias AA, Pati RK (2014) Reverse logistics in the pharmaceuticals industry: a systemic analysis. The International Journal of Logistics Management 25(2):379-398. https://doi.org/10.1108/ IJLM-08-2012-0073

Navadhi (2019) In Global Pharmaceuticals Industry Analysis and Trends 2023 1-7. Navahi Intelligence Rediscovered. https://doi.org/ GlobalPharmaceuticalsIndustryAnalysisandTrends2023

Pakdeechoho N, Sukhotu V (2018) Sustainable supply chain collaboration: incentives in emerging economies. J Manuf Technol Manag 29(2):273-294. https://doi.org/10.1108/JMTM-05-2017-0081

Paula IC, Campos EAR, Pagani RN, Guarnieri P, Kaviani MA (2019) Are collaboration and trust sources for innovation in the reverse logistics ? Insights from a systematic literature review. Supply Chain Management: An International Journal 25:176-222. https:// doi.org/10.1108/SCM-03-2018-0129 
Pereira AL, Silva JTM, Teixeira LAA (2012) Healthcare waste reverse logistics: a case study of Brazilian public hospitals. Int Bus Manag 6(2):95-98. https://doi.org/10.3923/ibm.2012.95.98

Pereira AL, de Vasconcelos Barros RT, Pereira SR (2017) Pharmacopollution and Household Waste Medicine (HWM): how reverse logistics is environmentally important to Brazil. Environ Sci Pollut Res 24(31):24061-24075. https://doi.org/10.1007/s11356017-0097-9

Pinto GMF, da Silva KR, Pereira, R. de F. A. B., \& Sampaio, S. I. (2014) Estudo do descarte residencial de medicamentos vencidos na região de Paulínia (SP), Brasil. Engenharia Sanitaria e Ambiental 19(3): 219-224. https://doi.org/10.1590/S1413-41522014019000000472

Prakash C, Barua MK (2015) Integration of AHP-TOPSIS method for prioritizing the solutions of reverse logistics adoption to overcome its barriers under fuzzy environment. J Manuf Syst 37:599-615. https://doi.org/10.1016/j.jmsy.2015.03.001

Prakash C, Barua MK, Pandya KV (2015) Barriers analysis for reverse logistics implementation in Indian Electronics Industry using fuzzy analytic hierarchy process. Procedia Soc Behav Sci 189:91-102. https://doi.org/10.1016/j.sbspro.2015.03.203

Pumpinyo S, Nitivattananon V (2014) Investigation of barriers and factors affecting the reverse logistics of waste management practice: a case study in Thailand. Sustainability (Switzerland) 6(10):70487062. https://doi.org/10.3390/su6107048

Rahman S, Subramanian N (2012) Factors for implementing end-of-life computer recycling operations in reverse supply chains. Int J Prod Econ 140(1):239-248. https://doi.org/10.1016/j.ijpe.2011.07.019

Ravi V, Shankar R, Raci V, Shankar R (2005) Analysis of interactions among the barriers of reverse logistics. Technol Forecast Soc Chang 72(8):1011-1029. https://doi.org/10.1016/j.techfore.2004.07.002

Remondi FA, Grochocki MH (2015) Assistência farmacêutica e o controle social. Conselho Regional de Farmácia do Estado do Paraná e Conselho Estadual de Saúde do Paraná 2. ed. - Curitiba: CRF/CES 86

Rogers DS, Tibben-lembke R (2001) An examination of reverse logistics practices. J Bus Logist 22(2):129-148. https://doi.org/10.1002/j. 2158-1592.2001.tb00158.x

Ruhoy IS, Daughton CG (2008) Beyond the medicine cabinet: an analysis of where and why medications accumulate. Environ Int 34(8): 1157-1169. https://doi.org/10.1016/j.envint.2008.05.002

Saravanan S, Manoj TM (2016) Reverse logistic disposal practices of household pharmaceutical medicines and its impact on environment in Trichy, Tamilnadu, India. International Research Journal of Pharmacy 7(6):66-70. https://doi.org/10.7897/2230-8407.07666

Shaharudin MR, Zailani S, Tan KC (2015) Barriers to product returns and recovery management in a developing country: investigation using multiple methods. J Clean Prod 96:220-232. https://doi.org/10. 1016/j.jclepro.2013.12.071

Sharma SK, Panda BN, Mahapatra SS, Sahu S (2011) Analysis of barriers for reverse logistics an Indian perspective. International Journal of Modeling and Optimization 1(2)

Shen L, Govindan K, Shankar M (2015) Evaluation of barriers of corporate social responsibility using an analytical hierarchy process under a fuzzy environment-a textile case. Sustainability (Switzerland) 7(3):3493-3514. https://doi.org/10.3390/su7033493

Shi X, Li LX, Yang L, Li Z, Choi JY (2012) Information flow in reverse logistics: an industrial information integration study. Inf Technol Manag 13(4):217-232. https://doi.org/10.1007/s10799-012-0116-y
Sirisawat P, Kiatcharoenpol T (2018) Fuzzy AHP-TOPSIS approaches to prioritizing solutions for reverse logistics barriers. Comput Ind Eng 117(April 2017):303-318. https://doi.org/10.1016/j.cie.2018.01. 015

Sivakumar K, Jeyapaul R, Vimal KEK, Ravi P (2018) A DEMATEL approach for evaluating barriers for sustainable end-of-life practices. https://doi.org/10.1108/JMTM-08-2017-0164

Soosay CA, Hyland P (2015) A decade of supply chain collaboration and directions for future research. Supply Chain Management: An International Journal 20(6):613-630. https://doi.org/10.1108/SCM06-2015-0217

Tewari S, Jindal R, Kho YL, Eo S, Choi K (2013) Major pharmaceutical residues in wastewater treatment plants and receiving waters in Bangkok, Thailand, and associated ecological risks. Chemosphere 91(5):697-704. https://doi.org/10.1016/j.chemosphere.2012.12.042

Thach AV, Brown CM, Pope N (2013) Consumer perceptions about a community pharmacy-based medication take back program. J Environ Manag 127:23-27. https://doi.org/10.1016/j.jenvman. 2013.04.025

Toh MR, Chew L (2017) Turning waste medicines to cost savings: a pilot study on the feasibility of medication recycling as a solution to drug wastage. Palliat Med 31(1):35-41. https://doi.org/10.1177/ 0269216316639798

Tong AYC, Peake BM, Braund R (2011) Disposal practices for unused medications around the world. Environ Int 37:292-298. https://doi. org/10.1016/j.envint.2010.10.002

Van Der Wiel A, Bossink B, Masurel E (2012) Reverse logistics for waste reduction in cradle-to-cradle-oriented firms: waste management strategies in the Dutch metal industry. Int J Technol Manag 60(1/2):96. https://doi.org/10.1504/IJTM.2012.049108

Vellinga A, Cormican S, Driscoll J, Furey M, O’Sullivan M, Cormican M (2014) Public practice regarding disposal of unused medicines in Ireland. Sci Total Environ 478:98-102. https://doi.org/10.1016/j. scitotenv.2014.01.085

Viegas CV, Bond A, Vaz CR, Bertolo RJ (2019) Reverse flows within the pharmaceutical supply chain: a classificatory review from the perspective of end-of-use and end-of-life medicines. J Clean Prod 238: 117719. https://doi.org/10.1016/j.jclepro.2019.117719

Waqas M, Dong Q, Ahmad N, Zhu Y (2018) Critical barriers to implementation of reverse logistics in the manufacturing industry : a case study of a developing country. Sustainability 10 (November): $1-25$. https://doi.org/10.3390/su10114202

Xia X, Govindan K, Zhu Q (2015) Analyzing internal barriers for automotive parts remanufacturers in China using grey-DEMATEL approach. J Clean Prod 87:811-825. https://doi.org/10.1016/j.jclepro. 2014.09.044

Zhou Y, Wu S, Zhou H, Huang H, Zhao J, Deng Y, Wang H, Yang Y, Yang J, Luo L (2018) Chiral pharmaceuticals: environment sources, potential human health impacts, remediation technologies and future perspective. Environ Int 121(June):523-537. https://doi.org/10. 1016/j.envint.2018.09.041

Publisher's note Springer Nature remains neutral with regard to jurisdictional claims in published maps and institutional affiliations. 